\title{
Model Pembelajaran Kooperatif Tipe Take and Give Meningkatkan Prestasi Belajar Siswa pada Mata Pelajaran Ilmu Pengetahuan Sosial
}

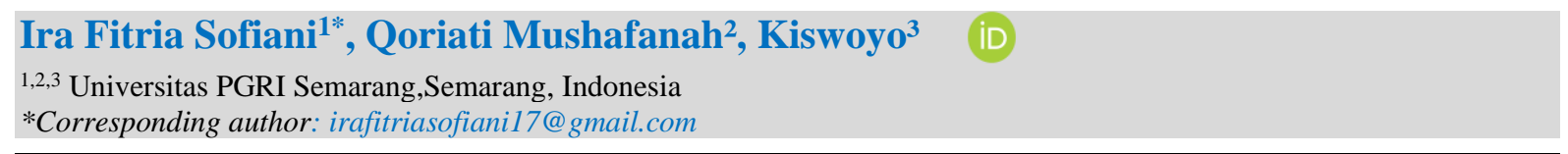

\begin{abstract}
Abstrak
Rendahnya prestasi belajar siswa pada mata pelajaran ilmu pengetahuan sosial (IPS) yang disebabkan karena siswa kurang tertarik dengan materi karena metode yang tidak mendukung sehingga pembelajaran tidak efektif. Tujuan penelitian ini menganalisis peningkatan prestasi belajar pada mata pelajaran IPS kelas IV pada saat pembelajaran daring dengan penerapan model pembelajaran kooperatif tipe take and give Jenis penelitian ini adalah penelitian kualitatif. Populasi penelitian adalah kelas IV yang terdiri dari 27 siswa. Data dalam penelitian ini diperoleh melalui dokumentasi, observasi, dan wawancara. Hasil penelitian menunjukkan bahwa siswa menjadi lebih aktif berkomentar di grup whatsapp ketika merasa ingin tahu, menanyakan hal yang belum dipahami, dan menanyakan apakah jawabannya betul atau tidak. Siswa merasa lebih tertarik karena penyajian gambar disajikan dalam bentuk kartu yang tentunya berbeda dengan gambar yang biasanya dikirim oleh guru yang berasal dari google. Prestasi belajar siswa juga meningkat karena siswa belajar melalui proses mengamati gambar, menganalisis informasi, mengumpulkan informasi, mengkomunikasikan kepada teman pasangannya dan secara otomatis melakukan diskusi untuk mencocokkan apakah kartunya merupakan pasangan yang benar. Berdasarkan hasil penelitian, dapat disimpulkan bahwa penerapan model pembelajaran take and give meningkatkan prestasi belajar siswa kelas IV pada mata pelajaran ilmu pengetahuan sosial (IPS) selama pembelajaran daring.
\end{abstract}

Kata kunci: Model Take And Give, IPS

\section{Abstract}

The low learning achievement of students in social science subjects (IPS) is caused because students are less interested in the material. After all, the method does not support so that learning is not effective. The purpose of this study is to analyze the increase in learning achievement in social studies subjects for class IV during online learning by applying the take and give a type of cooperative learning model. This type of research is qualitative research. The research population is class IV which consists of 27 students. The data in this study were obtained through documentation, observation, and interviews. The results showed that students became more active in commenting in the Whatsapp group when they felt curious, asked things they did not understand, and asked whether the answer was correct or not. Students feel more interested because the presentation of images is presented in the form of cards which is certainly different from the images that are usually sent by teachers from Google. Student achievement also increases because students learn through the process of observing pictures, analyzing information, gathering information, communicating to their partner's friends, and automatically conducting discussions to match whether the cards are the correct pairs. Based on the results of the study, it can be concluded that the application of the take and give learning model improves the learning achievement of fourth-grade students in social science subjects (IPS) during online learning.

Keywords: Take and Give Model, Social Science

\section{INTRODUCTION}

Ilmu Pengetahuan Sosial (IPS) merupakan salah satu mata pelajaran yang wajib diajarkan dalam setiap jenjang pendidikan khususnya di sekolah dasar. IPS merupakan salah satu mata pelajaran yang diberikan di sekolah dasar yang mengkaji seperangkat peristiwa, fakta, konsep, dan generalisasi yang berkaitan dengan isu sosial (Meiyani et al., 2017; Rusmawan, 2013; Sawitri et al., 2018; Sulfemi \& Mayasari, 2019). Tujuan dari pembelajaran IPS adalah untuk mendidik dan memberi bekal, minat, kemampuan dan lingkungan, serta berbagai bekal bagi siswa untuk melanjutkan pendidikan ke jenjang yang lebih tinggi (Anjarsari et al., 2017; Dewi et al., 2017; Maulida et al., 2020; Putra et al., 2017). Untuk

$\begin{array}{lll}\text { History: } & & \text { Publisher: Undiksha Press } \\ \text { Received } & : 22 \text { November } 2020 & \text { Licensed: This work is licensed under } \\ \text { Revised } & : 11 \text { Desember } 2020 & \text { a Creative Commons Attribution 3.0 License } \\ \text { Accepted } & : 26 \text { April } 2021 & \text { CC (C) (O) } \\ \text { Published } & : 25 \text { Mei } 2021 & \end{array}$


menunjang tercapainya tujuan IPS tersebut harus didukung oleh iklim pembelajaran yang kondusif.

Namun, kenyataan yang terjadi di lapangan berbeda. Berdasarkan hasil wawancara dengan guru kelas diketahui bahwa terdapat beberapa kendala dalam proses belajar mengajar. Salah satu kendala utama yang dihadapi oleh guru adalah prestasi belajar siswa tidak maksimal, karena siswa kurang antusias belajar, siswa lebih cenderung menerima apa saja yang disampaikan oleh guru, diam dan enggan dalam mengemukakan pertanyaan maupun pendapat. Kendala itu muncul karena pembelajaran yang dilakukan oleh guru bersifat monoton, berpusat pada guru, dan kurang menarik. Sehingga siswa menjadi kurang tertarik dengan pembelajaran yang dilakukan oleh guru di kelas. Hal tersebut diungkapkan berdasarkan hasil pengamatan guru dikelas, prestasi belajar siswa kelas IV tersebut masih tergolong rendah dengan menunjukkan gejala-gejala diantaranya ialah 1) tidak ada keinginan siswa untuk bertanya dalam proses belajar mengajar, 2) apabila ditanya siswa tidak mampu menjawab, 3) siswa tidak serius dalam mengerjakan tugas atau latihan yang diberikan oleh guru dan tidak mau mengerjakan PR yang diberikan guru, 4) siswa cenderung pasif selama proses belajar mengajar. Selain itu, hasil belajar siswa pada muatan IPS juga masih ada yang berada di bawah KKM.

Permasalahan tersebut jika dibiarkan maka akan berdampak buruk pada proses pembelajaran dan hasil belajar di sekolah tersebut. Maka diperlukan solusi untuk permasalahan tersebut. Salah satu solusi yang dapat dilakukan ialah menerapkan model pembelajaran take and give. Model pembelajaran take and give adalah salah satu model pembelajaran kooperatif yang dapat diterapkan dan sesuai dengan karakteristik siswa SD yang beragam (Gustia \& Noviana, 2019; Pariawan et al., 2013). Model pembelajaran take and give adalah model pembelajaran kooperatif yang didukung oleh penyajian data yang diawali dengan pemberian kartu kepada siswa yang di dalam kartu itu sendiri ada catatan yang harus dikuasai atau dihafal oleh masing-masing siswa (Ritongan, 2019; Seputra, 2020; Yuliastini et al., 2015). Siswa kemudian mencari pasangannya masing-masing untuk bertukar pengetahuan yang ada padanya sesuai dengan yang didapatnya di kartu, lalu kegiatan pembelajaran diakhiri dengan mengevaluasi siswa dengan menanyakan pengetahuan yang ada padanya dan yang dia terima dari pasangannya.

Model pembelajaran take and give memberikan kesempatan kepada siswa untuk berinteraksi dengan teman dikelompoknya dalam menyelesaikan permasalahan yang dihadapi sehingga mereka dapat saling berbagi pengetahuan, yang kemampuannya kurang dapat bertanya kepada teman yang lebih mengerti dikelompoknya. Hal ini sesuai dengan kelebihan dari model pembelajaran kooperatif tipe take and give yaitu dapat melatih siswa untuk bekerja sama dan menghargai kemampuan orang lain, melatih siswa untuk berinteraksi secara baik dengan teman sekelas, dan meningkatkan tanggung jawab siswa, sebab masing-masing siswa dibebani pertanggungjawaban atas kartunya masing-masing. Belum adanya penelitian mendalam mengenai model pembelajaran take and give di sekolah dasar pada pembelajaran daring.

Beberapa penelitian relevan dengan penelitian ini seperti penelitian yang dilakukan oleh (Gustia \& Noviana, 2019) menemukan bahwa dengan menerapkan model pembelajaran kooperatif tipe Take dan Give dapat meningkatkan hasil belajar IPS siswa kelas. Kemudian penelitian lain juga dilakukan dan menemukan bahwa terdapat pengaruh yang signifikan model pembelajaran Take and Give berbantuan media Mind Mapping terhadap hasil belajar IPA siswa kelas V SD (Seputra, 2020). Penelitian lain juga dilakukan dan menemukan bahwa model pembelajaran kooperatif tipe take and give berbantuan multimedia interaktif berpengaruh terhadap hasil belajar siswa pada mata pelajaran IPS (Yuliastini et al., 2015). Tujuan penelitian ini untuk menganalisis peningkatan prestasi belajar pada mata pelajaran 
IPS kelas IV pada saat pembelajaran daring dengan penerapan model pembelajaran kooperatif tipe take and give.

\section{MATERIALS AND METHODS}

Penelitian ini menggunakan penelitian kualitatif dengan jenis penelitian deskriptif kualitatif (Sugiyono, 2016). Penelitian kualitatif adalah penelitian untuk meneliti kondisi yang sebenarnya dan berkaitan dengan perilaku, persepsi, motivasi, dan lain-lain secara nyata dengan cara deskriptif dalam bentuk kata-kata dan bahasa. Penelitian dilaksanakan di SDN 01 Kenteng Toroh Grobogan. Populasi penelitian adalah kelas IV yang terdiri dari 27 siswa. Data yang diperoleh dalam penelitian ini berasal dari kegiatan observasi untuk mengamati aktivitas siswa dalam kegiatan pembelajaran IPS dengan model pembelajaran konvensional yang telah diterapkan dan model pembelajaran kooperatif tipe take and give. Selain itu, data juga didapatkan dari hasil wawancara dengan kepala sekolah, guru kelas dan siswa kelas IV SDN 01 Kenteng yang menjadi subjek penelitian ini.

\section{RESULTS AND DISCUSSION}

Sebelum melaksanakan observasi kegiatan pembelajaran secara daring, peneliti melakukan wawancara terlebih dahulu dengan kepala sekolah dan guru kelas. Setelah melakukan wawancara dengan kepala sekolah, peneliti mendapatkan informasi terkait profil sekolah, model pembelajaran yang sering digunakan oleh guru untuk menjelaskan materimateri pada mata pelajaran IPS. Berdasarkan wawancara yang dilakukan, kepala sekolah mengatakan bahwa selama masa pandemi terdapat kesulitan dalam mewujudkan visi dan misi SDN 1 Kenteng karena guru tidak bisa memantau secara langsung kegiatan pembelajaran, sehingga beberapa visi tidak dapat tercapai. Contoh misi yang tidak dapat tercapai adalah menciptakan suasana pembelajaran yang aktif, kreatif, dan inovatif. Guru lebih sering menggunakan metode pembelajaran ceramah dan mengamati secara langsung apa yang ada di sekitarnya dengan bantuan orangtua/ wali murid. Metode ceramah digunakan karena dianggap paling mudah untuk dilakukan dalam kondisi belajar secara daring yang membatasi guru untuk memantau perkembangan peserta didik. Menurut kepala sekolah, guru melakukan kegiatan pembelajaran sesederhana mungkin agar pembelajaran dapat tersampaikan. Hal tersebut tentunya yang mengakibatkan prestasi belajar IPS menjadi rendah.

Salah satu hal yang dilakukan guru untuk mengatasi kesulitan tersebut adalah dengan memberikan soal-soal latihan untuk perbaikan dan pengayaan agar siswa dapat berlatih mengingat dan memahami materi. Faktor-faktor yang mempengaruhi prestasi belajar siswa antara lain tingkat penguasaan materi oleh guru, metode atau model pembelajaran yang digunakan, tingkat ketertarikan siswa terhadap penyajian materi, media dan sarana prasarana untuk mendukung pelaksanaan model pembelajaran. Guru biasanya menggunakan media belajar sederhana berupa gambar yang berasal dari buku atau google. Siswa diminta mengamati gambar tersebut lalu mengerjakan soal. Sarana dan prasarana tidak digunakan sama sekali selama masa pandemi karena siswa berada di rumah sehingga guru tidak bisa memanfaatkan sarana dan prasarana yang ada di sekolah. Untuk informasi mengenai profil sekolah bisa dilihat pada lampiran.

Setelah melakukan wawancara dengan kepala sekolah, peneliti melakukan wawancara dengan guru kelas IV. Peneliti melakukan wawancara sebelum dan sesudah penerapan model take and give. Berdasarkan wawancara sebelum penerapan model, peneliti memperoleh informasi bahwa siswa kurang tertarik dengan materi IPS karena beberapa faktor. Contohnya kurangnya penggunaan media yang bervariasi, guru hanya mengirim gambar sebagai contoh, siswa tidak diminta memberikan timbal balik. Selain itu faktor lain yang menyebabkan 
pembelajaran kurang efektif adalah penyajian gambar kurang inovatif, sarana dan prasarana tidak dimanfaatkan akibat pembelajaran secara daring. Menurut guru, faktor lain yang dapat mempengaruhi prestasi belajar siswa adalah model dan media yang dipilih serta keterampilan guru dalam menjelaskan materi. Guru biasanya menggunakan lingkungan dan alat peraga untuk menjelaskan materi, akan tetapi selama pembelajaran daring guru hanya menggunakan gambar dari google untuk menjelaskan materi.

Setelah melakukan penerapan model pembelajaran, peneliti melakukan wawancara kembali dengan guru kelas IV SDN 1 Kenteng untuk memperoleh informasi terkait penerapan model pembelajaran take and give terhadap prestasi belajar siswa pada materi sumber daya alam. Guru mengatakan bahwa siswa menjadi lebih aktif berkomentar di grup whatsapp ketika merasa ingin tahu, menanyakan hal yang belum dipahami, dan menanyakan apakah jawabannya betul atau tidak. Siswa merasa lebih tertarik karena penyajian gambar disajikan dalam bentuk kartu yang tentunya berbeda dengan gambar yang biasanya dikirim oleh guru yang berasal dari google. Prestasi belajar siswa juga meningkat karena siswa belajar melalui proses mengamati gambar, menganalisis informasi, mengumpulkan informasi, mengkomunikasikan kepada teman pasangannya dan secara otomatis melakukan diskusi untuk mencocokkan apakah kartunya merupakan pasangan yang benar. Berdasarkan hasil wawancara dengan kepala sekolah, dan guru peneliti dapat menyimpulkan bahwa faktor yang mempengaruhi peningkatan prestasi belajar adalah media, model, sarana prasarana, penyajian contoh, dan sistem soal antara guru dan siswa sangat penting dan saling berkesinambungan.

Peningkatan prestasi belajar pada mata pelajaran IPS dikarenakan penerapan model pembelajaran kooperatif tipe take and give membuat siswa telibat langsung pada proses pembelajaran sehingga dapat meningkatkan motivasi siswa dalam proses belajar mengajar. Penerapan model pembelajaran kooperatif take and give pada kelas eksperimen dapat mendorong siswa lebih aktif di kelas seperti aktif dalam diskusi kelompok yaitu saling memberi dan menerima materi pelajaran. Aktivitas tersebut dilakukan agar siswa memperoleh pengalaman belajar dengan teman sebayanya. Hal ini terlihat pada keaktifan siswa berkomentar di grup whatsapp ketika merasa ingin tahu, menanyakan hal yang belum dipahami, dan menanyakan apakah jawabannya betul atau tidak. Siswa juga menjadi tertarik pada pembelajaran IPS dan tidak menganggap pelajaran IPS itu membosankan. Hal itu dikarenakan dalam penerapan model pembelajaran kooperatif tipe take and give guru menjayjikan gambar dalam bentuk kartu yang tentunya berbeda dengan gambar yang biasanya dikirim oleh guru yang berasal dari google. Dengan keaktifan siswa dalam mencari pengetahuannya sendiri maka paradigma pembelajaran berubah menjadi berpusat pada siswa, sehingga guru tidak lagi mendominasi kegiatan pembelajaran (Agustina et al., 2017; Ritongan, 2019; Seputra, 2020). Guru hanya bertindak sebagai fasilitator, motivator, dan pembimbing jalannya diskusi yang dilakukan siswa. Dengan demikian, materi yang dipelajari lebih lama diingat dan lebih bermakna bagi siswa.

Beberapa komponen penting dalam model pembelajaran take and give yaitu penguasaan materi melalui kartu keterampilan bekerja berpasangan dan sharing informasi, serta evaluasi yang bertujuan untuk mengetahui pemahaman atau penguasaan siswa terhadap materi yang diberikan di dalam kartu dan kartu pasangannya (Ritongan, 2019; Sugiantari et al., 2016). Model pembelajaran take and give memiliki beberapa kelebihan diantaranya 1) peserta didik akan lebih cepat memahami penguasaan materi dan informasi karena mendapatkan informasi dari guru dan peserta didk yang lain; 2) dapat menghemat waktu dalam pemahaman dan penguasaan peserta didik akan materi; 3) meningkatkan kemampuan untuk bekerja sama dan bersosialisasi; 4) melatih kepekaan diri, empati melalui variasi perbedaan sikap-tingkah laku selama bekerja sama; 5) mengurangi rasa kecemasan dan menumbuhkan rasa percaya diri; 6) meningkatkan motivasi belajar (partisispasi dan minat), 
harga diri dan sikap-tingkah laku yang positif serta meningkatkan prestasi belajarnya (Agustina et al., 2017; Ritongan, 2019).

Beberapa penelitian relevan dengan penelitian ini seperti penelitian yang dilakukan oleh (Gustia \& Noviana, 2019) menemukan bahwa dengan menerapkan model pembelajaran kooperatif tipe Take dan Give dapat meningkatkan hasil belajar IPS siswa kelas. Kemudian penelitian lain juga dilakukan dan menemukan bahwa terdapat pengaruh yang signifikan model pembelajaran Take and Give berbantuan media Mind Mapping terhadap hasil belajar IPA siswa kelas V SD (Seputra, 2020). Penelitian lain juga dilakukan dan menemukan bahwa model pembelajaran kooperatif tipe take and give berbantuan multimedia interaktif berpengaruh terhadap hasil belajar siswa pada mata pelajaran IPS (Yuliastini et al., 2015).

\section{CONCLUSION}

Guru yang menyebutkan bahwa setelah penerapan model pembelajaran take and give prestasi belajar anak meningkat yang dapat ditunjukkan melalui daftar nilai sebelum dan sesudah penerapan model pembelajaran take and give. Sehingga dapat diketahui bahwa penerapan model pembelajaran take and give meningkatkan prestasi belajar siswa kelas IV pada mata pelajaran ilmu pengetahuan sosial (IPS) selama pembelajaran daring.

\section{REFERENCES}

Agustina, N. K. A. R., Suartama, I. K., \& Japa, I. G. N. (2017). Model Pembelajaran Take And Give Berbasis Kebudayaan Lokal Terhadap Hasil Belajar Pkn Kelas V SD. MIMBAR PGSD Undiksha, 5(2). http://dx.doi.org/10.23887/jjpgsd.v5i2.10983.

Anjarsari, K. Y., Suniasih, N. W., \& Sujana, I. W. (2017). Pengaruh Model Pembelajaran Talking Chips Berbasis Tri Hita Karana Terhadap Kompetensi Pengetahuan IPS. Mimbar PGSD, 5(2). http://dx.doi.org/10.23887/jjpgsd.v5i2.10659.

Dewi, N. P. D. A., Wiyasa, I. K. N., \& Asri, I. G. A. A. S. (2017). Pengaruh Model Kooperatif Talking Stick Berbantu Question Card terhadap Kompetensi Pengetahuan IPS Siswa kelas IV. Mimbar PGSD, 5(2). http://dx.doi.org/10.23887/jjpgsd.v5i2.10790.

Gustia, D. D., \& Noviana, E. (2019). Penerapan Model Pembelajaran Kooperatif Tipe Take And Give Untuk Meningkatkan Hasil Belajar Ips Siswa Kelas Iii Sdn 192 Pekanbaru. Jurnal PAJAR (Pendidikan Dan Pengajaran), 3(2). http://dx.doi.org/10.33578/pjr.v3i2.6444.

Maulida, I., Dibia, I. K., \& Astawan, I. G. (2020). The Development of Social Attitude Assessment Instrument and Social Studies Learning Outcomes Grade IV on Theme of Indahnya Keragaman di Negeriku. Indonesian Journal Of Educational Research and Review, 3(1), 12. https://doi.org/10.23887/ijerr.v3i2.25823.

Meiyani, K. S., Putra, M., \& Suadnyana, I. N. (2017). Pengaruh Model Quantum Teaching Melalui Karyawisata Terhadap Penguasaan Kompetensi Pengetahuan IPS Siswa $\begin{array}{lllll}\text { Kelas } & \text { V. MIMBAR }\end{array}$ http://dx.doi.org/10.23887/jjpgsd.v5i2.10836.

Pariawan, P. E., Putra, D. K. N. S., \& Abadi, I. G. S. (2013). Pengaruh Model Pembelajaran Take and Give Berbasis Resolusi Konflik terhadap Hasil Belajar IPS Siswa Kelas V SD N 26 Pemecutan. Mimbar PGSD Undiksha, 1(1). http://dx.doi.org/10.23887/jjpgsd.v1i1.1206.

Putra, M., Darsana, I. W., \& Darmayanti, N. K. A. M. (2017). Pengaruh Model Pembelajaran Numbered Head Together Berbasis Reinforcement Terhadap Penguasaan Kompetensi 
Pengetahuan Ips Siswa Kelas V. International Journal of Elementary Education, 1(2), 145-152. http://dx.doi.org/10.23887/ijee.v1i2.11607.

Ritongan, H. (2019). Efektivitas Model Pembelajaran Take and Give Terhadap Kemampuan Komunikasi Matematis. JURNAL MathEdu (Mathematic Education Journal), 2(2). http://journal.ipts.ac.id/index.php/MathEdu/article/view/963.

Rusmawan, R. (2013). Faktor yang memengaruhi kesulitan belajar IPS siswa sekolah dasar. Jurnal Cakrawala Pendidikan, 2. https://journal.uny.ac.id/index.php/cp/article/view/1487/pdf.

Sawitri, N. N. R., Suniasih, N. W., \& Sujana, I. W. (2018). Pengaruh Model Pembelajaran Circ Berbasis Karakter Terhadap Kompetensi Pengetahuan Ips Siswa. Jurnal Mimbar Ilmu, 23(2). http://dx.doi.org/10.23887/mi.v23i2.16420.

Seputra, I. K. W. (2020). Model Pembelajaran Take and Give Berbantuan Media Mind Mapping Berpengaruh Terhadap Hasil Belajar IPA. Jurnal Ilmiah Pendidikan Profesi Guru, 3(3), 434. https://doi.org/10.23887/jippg.v3i3.29426.

Sugiantari, P., Murda, I. N., \& Rati, N. W. (2016). Penerapan Take And Give Berbantuan Mind Mapping Untuk Meningkatkan Keaktifan Dan Hasil Belajar Kelas Iv. Mimbar Pgsd Undiksha, 4(1). http://dx.doi.org/10.23887/jjpgsd.v4i1.7269.

Sugiyono. (2016). Metode Penelitian Kualitatif, Kuantitatif, dan R\&D. Alfabeta.

Sulfemi, W. B., \& Mayasari, N. (2019). Peranan model pembelajaran value clarificationtechnique berbantuan media audio visual untuk meningkatkan hasil belajar IPS. Jurnal Pendidikan, 20(1), 53. https://doi.org/10.33830/jp.v20i1.772.2019.

Yuliastini, N. L. G. S., Tastra, I. D. K., \& Suditha, I. W. R. (2015). Pengaruh Model Take And Give Berbantuan Multimedia Interaktif Terhadap Hasil Belajar Ips. Jurnal Edutech Undiksha, 3(1). http://dx.doi.org/10.23887/jeu.v3i1.5599. 